\title{
INFECÇÃO PELO HELICOBACTER PYLORI: prevalência e associação com lesões gástricas
}

DESCRITORES - Infecções por Helicobacter. Gastropatias.

A infecção pelo H. pylori acomete mais da metade da população mundial, sendo mais freqüente nos países subdesenvolvidos onde sua prevalência nos adultos alcança, segundo alguns estudos, índices de até $80 \%$, valores estes significativamente superiores aos observados nos países industrializados $(20 \% \text { a } 50 \%)^{(3,4)}$.

Sabe-se que a infecção por esse microrganismo determina uma importante inflamação, aguda e crônica da mucosa gástrica que, quando não tratada, permanece para sempre, sendo raramente eliminada de forma espontânea ${ }^{(5)}$. A gastrite crônica não-atrófica ocasionada pelo $H$. pylori pode evoluir para gastrite atrófica, metaplasia intestinal e displasia ${ }^{(1,5)}$.

Habitualmente a gastrite crônica é uma condição assintomática. Apesar da tentativa de associá-la com a dispepsia funcional, a maioria dos estudos não encontra correlação entre sintomas gastrointestinais e a extensão ou a gravidade da gastrite $^{(6)}$. Desse modo, o principal significado clínico da gastrite crônica associada ao H. pylori reside na sua estreita correlação com a úlcera péptica e com o carcinoma e linfoma gástricos.

Existem fortes evidências, provenientes de estudos de metanálise, que confirmam o papel do H. pylori na carcinogênese gástrica. Em estudo prospectivo realizado no Japão, UEMURA et al. ${ }^{(13)}$ relataram desenvolvimento de câncer gástrico em 36 (2,9\%) de 1.246 indivíduos portadores da bactéria e em nenhum de 280 não-infectados. Foi observado que entre os pacientes infectados, aqueles com atrofia gástrica intensa, gastrite predominante do corpo e metaplasia intestinal apresentavam risco significativamente mais elevado para o aparecimento de câncer gástrico. Vários outros trabalhos, realizados posteriormente, demonstraram também risco aumentado para o desenvolvimento de neoplasia gástrica em indivíduos infectados, confirmando os achados do grupo japonês ${ }^{(8,12)}$.

Ainda que a incidência e a mortalidade do câncer gástrico estejam em queda, essa neoplasia continua sendo uma das principais causas de morte por câncer em muitas regiões do mundo, inclusive no $\mathrm{Brasil}^{(7)}$. A compreensão sobre a epidemiologia e a patogênese dessa doença é fundamental para a identificação de agentes causais e o desenvolvimento de estratégias de prevenção racionais. O reconhecimento do papel do $H$. pylori na cascata da carcinogênese gástrica propiciou enorme avanço nos nossos conhecimentos, ajudando a elucidar inúmeros aspectos fisiopatológicos ${ }^{(6,8,12,13)}$. Entretanto, alguns aspectos dessa associação permanecem bastante controversos sendo necessários novos estudos que investiguem a real virulência do microorganismo, a genética do hospedeiro, além de fatores ambientais e epidemiológicos

Neste número a revista ARQUIVOS de GASTROENTEROLOGIA publica um excelente trabalho realizado na Universidade Federal de Santa Maria, RS, onde MULLER et al. ${ }^{(11)}$ estudaram a prevalência da infecção pelo H. pylori e das lesões precursoras do câncer gástrico em pacientes dispépticos. Os autores analisaram retrospectivamente biopsias gástricas de 2.019 pacientes submetidos a endoscopia digestiva por apresentarem queixas dispépticas. Foi observada alta prevalência da infecção pelo $H$. pylori nas biopsias analisadas através do método de coloração de hematoxilina-eosina (H-E). É necessário ressaltar que o diagnóstico do $H$. pylori realizado exclusivamente através dessa coloração apresenta importantes limitações. MOLYNEUX e HARRIS ${ }^{(10)}$ demonstraram que a coloração por H-E para o diagnóstico do H. pylori, quando usada isoladamente, apresenta índices razoáveis de falso-positivos e falso-negativos. Importante ainda salientar que a elevada prevalência da infecção encontrada pelos autores é proveniente de amostragem constituída de indivíduos sintomáticos, submetidos a endoscopia digestiva e, portanto, não representativa da população geral.

MULLER et al. ${ }^{(11)}$ observaram que a presença do H. pylori determinou probabilidade 10 vezes maior para o desenvolvimento de lesões gástricas, corroborando com os dados da literatura ${ }^{(1,5,6)}$. Por outro lado, não foi demonstrado que a infecção seja um fator determinante de risco para a ocorrência de gastrite atrófica e metaplasia intestinal. A partir desses achados, os autores concluem que, provavelmente, outros fatores, além da simples presença da bactéria, participem da patogênese do câncer gástrico.

De fato, o câncer gástrico é atualmente considerado uma doença multifatorial ${ }^{(1,6)}$. O importante papel desempenhado pelo $H$. pylori na carcinogênese gástrica é inegável e consensual em todo o mundo ${ }^{(6,8)}$. Entretanto, acredita-se que para o desenvolvimento da neoplasia no estômago sejam necessários outros fatores, além da infecção gástrica ${ }^{(9)}$. A gravidade das lesões gástricas e o eventual resultado clínico da infecção parecem ser determinados pela combinação de fatores genéticos do hospedeiro, patogenicidade da bactéria e fatores ambientais ${ }^{(1,2,9,12)}$. Estudos que visem determinar os mecanismos de virulência do H. pylori, através da biologia molecular e fatores genéticos do indivíduo infectado, provavelmente elucidarão, em 
futuro próximo, alguns aspectos ainda desconhecidos da patogênese do câncer gástrico. Tais estudos também serão de grande importância para o reconhecimento de estratégias adequadas para a prevenção das lesões graves e precursoras da neoplasia nos indivíduos infectados.

Os achados publicados pelo grupo da Universidade de Santa Maria ${ }^{(11)}$ são de enorme relevância e vêm contribuir para a melhor compreensão das conseqüências da infecção pelo $H$. pylori na população brasileira.
Novos trabalhos, nessa mesma linha de investigação, cuidadosamente planejados e com número grande de pacientes se fazem necessários em nosso país para que possamos conhecer a real prevalência da infecção nas diferentes regiões do Brasil e compreender melhor o papel do H. pylori no desencadeamento das lesões precursoras do carcinoma gástrico, doença ainda bastante freqüente no nosso meio.

Maria do Carmo Friche PASSOS*

Passos MCF. Helicobacter pylori infection: prevalence and association with gastric lesions. Arq Gastroenterol. 2007;44(2):91-2.

HEADINGS - Helicobacter infections. Stomach diseases.

\section{REFERÊNCIAS}

1. Ando T, Goto Y, Ishiguro K, Maeda O, Watanabe O, Ohmiya N, Niway, Hama-jima N, El-Omar E, Goto H. The interaction of host genetic factors and Helicobacter pylori infection. Inflammopharmacology. 2007;15:10-4.

2. Cabral MM, Oliveira CA, Mendes CM, Guerra J, Queiroz DM, Rocha GA, Rocha AM, Nogueira AM. Gastric epithelial cell proliferation and cagA status in Helicobacter pylori gastritis at different gastric sites. Scand J Gastroenterol. 2007;42:545-54

3. Castro LP, Coelho LG. Helicobacter pylori in South America. Can J Gastroenterol 1998;12:509-12.

4. Chey WD, Wong BC. Practice Parameters Committee Of The American College Of Gastroenterology. American College of Gastroenterology guideline on the management of Helicobacter pylori infection. Am J Gastroenterol. 2007.

5. Dixon MF. Prospects for intervention in gastric carcinogenesis: reversibility of gastric atrophy and intestinal metaplasia. Gut. 2001;49:2-4.
6. El-Omar EM, Chow WH, Rabkin CS. Gastric cancer and H. pylori: host genetics open the way. Gastroenterology. 2001;121:1002-4.

7. Instituto Nacional do Cancer - INCA. Estimativa 2006: incidência de câncer no Brasil. Rio de Janeiro: INCA; 2005.

8. Leung WK. Helicobacter pylori and gastric neoplasia. Contrib Microbiol. 2006;13:66-80.

9. Menaker RJ, Sharaf AA, Jones NL. Helicobacter pylori infection and gastric cancer: host, bug, environment, or all three? Curr Gastroenterol Rep. 2004;6:429-35.

10. Molyneux AJ, Harris MD. Helicobacter pylori in gastric biopsies--should you trust the pathology report? J R Coll Physicians Lond. 1993;27:119-20.

11. Muller LB, Fagundes RB, Moraes CC, Rampazzo A. Prevalência da infecção por Helicobacter pylori $\mathrm{e}$ das lesões precursoras do câncer gástrico em pacientes dispépticos. Arq Gastroenterol. 2007;44: 93-8.

12. Peter S, Beglinger C. Helicobacter pylori and gastric cancer: the causal relationship. Digestion. 2007;75:25-35.

13. Uemura N, Okamoto S, Yamamoto S, Matsumura N, Yamaguchi S, Yamakido M, Taniyama K, Sasaki N,Sclemper RJ. Helicobacter pylori infection and the development of gastric cancer. N Engl J Med. 2001;345:784-9.

* Departamento de Clínica Médica, Faculdade de Medicina da Universidade Federal de Minas Gerais, Belo Horizonte, MG. 